\title{
Systematic review of breast and complementary feeding in Ethiopia: a commentary
}

\author{
J. M. Moran ${ }^{1}$ - L. M. Puerto-Parejo ${ }^{1}$ \\ Published online: 31 January 2020 \\ ○) Springer-Verlag GmbH Germany, part of Springer Nature 2020
}

Keywords Breastfeeding $\cdot$ Complementary feeding $\cdot$ Meta-analysis $\cdot$ Systematic review $\cdot$ Research methodology

We read with interest the manuscript from Habtewold et al. that provides a national estimate of breast and complementary feeding practices and its predictors in Ethiopia [1]. We would like to highlight an inaccurate literature review performed in this study. Authors included in their study the cross-sectional study from Gultie and Sebsibie about determinants of suboptimal breastfeeding practice in Debre Berhan town, Ethiopia [2]. The study from Gultie and Sebsibie has been included in the meta-analysis as it reported both the prevalence and/or least adjusted associated factors of timely initiation of breastfeeding and the prevalence and/or least adjusted associated factors of exclusive breastfeeding. However, the study from Gultie and Sebsibie was retracted from the International Breastfeeding Journal in 2018 (online: 07 March 2018) because of significant overlap of both text and data with the Master's Thesis of Hilina Ketma, "Assessment of prevalence and determinants of suboptimal breastfeeding among mothers of children aged less than two years in Dire Dawa City Administration, Ethiopia, June 2013”, which was defended at the School of Graduate Studies, Addis Ababa University, in June 2013 [3]. Authors searched for studies published from October 2000 to April 2018 so the retraction note should be observed. We are aware that the exclusion of Gultie and Sebsibie study would not probably affect

The original publication can be read here: https://doi.org/10.1007/ s00394-018-1817-8

A reply to this letter to the Editor is available here: https://doi. org/10.1007/s00394-019-02172-5.

\section{J. M. Moran}

jmmorang@unex.es

1 Nursing Department, Metabolic Bone Diseases Research Group, Nursing and Occupational Therapy College, University of Extremadura, Avd. Universidad s/n, 10003 Cáceres, Spain the overall conclusion of Habtewold et al. study, but a good and accurate literature review is a key element of systematic reviews and meta-analysis and always needs to rely on highquality original studies.

Funding This research received no specific grant from any funding agency in the public, commercial or not-for-profit sectors.

\section{Compliance with ethical standards}

Conflict of interest The authors declare that they have no conflict of interest.

\section{References}

1. Habtewold TD, Mohammed SH, Endalamaw A et al (2019) Breast and complementary feeding in Ethiopia: new national evidence from systematic review and meta-analyses of studies in the past 10 years. Eur J Nutr 58:2565-2595. https://doi.org/10.1007/s0039 4-018-1817-8

2. Gultie T, Sebsibie G (2016) Determinants of suboptimal breastfeeding practice in Debre Berhan town, Ethiopia: a cross sectional study. Int Breastfeed J 11:15. https://doi.org/10.1186/s1300 6-016-0063-z

3. Gultie T, Sebsibie G (2018) Retraction note: determinants of suboptimal breastfeeding practice in Debre Berhan town, Ethiopia: a cross sectional study. Int Breastfeed J 13:13. https://doi. org/10.1186/s13006-018-0155-Z 